Article

\title{
Ethylene Separation via Hydrate Formation in W/O Emulsions
}

\section{Yong Pan, Huang Liu, Zhi Li, Bei Liu *, Qinglan Ma, Guangjin Chen, Changyu Sun, Lanying Yang and Xueteng Gao}

State Key Laboratory of Heavy Oil Processing, China University of Petroleum, Beijing 102249, China; E-Mails: 13051792239@163.com (Y.P.); luckboy3008@126.com (H.L.); 1z979157903@163.com (Z.L.); maq1@cup.edu.cn (Q.M.); gjchen@cup.edu.cn (G.C.); cysun@cup.edu.cn (C.S.); yanglanying@cup.edu.cn (L.Y.); gao674153496@163.com (X.G.)

* Author to whom correspondence should be addressed; E-Mail: liub@cup.edu.cn; Tel.: +86-10-8973-3252; Fax: +86-10-8973-2126.

Academic Editor: Pierre Trambouze

Received: 7 March 2015 / Accepted: 18 May 2015 / Published: 27 May 2015

\begin{abstract}
An hybrid absorption-hydration method was adopted to recover $\mathrm{C}_{2} \mathrm{H}_{4}$ from $\mathrm{C}_{2} \mathrm{H}_{4} / \mathrm{CH}_{4}$ binary gas mixtures and the hydrate formation conditions of $\mathrm{C}_{2} \mathrm{H}_{4} / \mathrm{CH}_{4}$ mixtures was studied experimentally in diesel in water (w/o) emulsions. Span 20 at a concentration of $1.0 \mathrm{wt} \%$ in the aqueous phase was added to form water in diesel emulsions before hydrate formation and then hydrate in diesel slurry was separated after hydrate formation. The influences of initial gas-liquid volume ratio (53-142), pressure (3.4-5.4 MPa), temperature $(274.15-278.15 \mathrm{~K})$, water cuts $(10-30 \mathrm{vol} \%)$, and the mole fraction of $\mathrm{C}_{2} \mathrm{H}_{4}$ in feed gas (13.19-80.44 mol\%) upon the $\mathrm{C}_{2} \mathrm{H}_{4}$ separation efficiency were systematically investigated. The experimental results show that ethylene can be enriched in hydrate slurry phase with high separation factor $(S)$ and recovery ratio $(R)$. Most hydrate formation finished in $20 \mathrm{~min}$, after that, the hydrate formation rate became very slow. The conclusion is useful for determining the suitable operation conditions when adopting an absorption-hydration method to separate $\mathrm{C}_{2} \mathrm{H}_{4} / \mathrm{CH}_{4}$.
\end{abstract}

Keywords: separation; hydrate; ethylene; methane; water in oil emulsion 


\section{Introduction}

Separation of C2 hydrocarbons from methane is a very important industrial process [1]. This is because the recovery of $\mathrm{C} 2$ hydrocarbons from methane not only upgrades the quality of natural gas (NG) for its efficient usage, but can also provide an alternative chemical source of $\mathrm{C} 2 \mathrm{~s}$ for further chemical processing and transformation. Furthermore, $\mathrm{C} 2 \mathrm{~s}$ are the main products of oxidative coupling of methane (OCM) in the process for converting NG into a more useful chemical feedstock, thus they certainly need to be separated from the un-reacted methane [2]. Now industrial hydrocarbon mixture separations mainly rely upon the energy-intensive distillation-based technologies, which represent a class of the most important and also the most costly processes in the chemical industry [3]. A new separation technology based on hydrate formation/dissociation might be an optional method for the separation of low boiling gas mixtures.

Gas hydrates are nonstoichiometric crystalline compounds composed of water and gases with small molecules [4]. The mechanism of hydrate-based gas separation is that some components can form hydrates more easily and thus be enriched in hydrate phase, therefore leading to the relative concentration of each component in the hydrate phase and that in the residual vapor phase be different [5]. An obvious advantage of hydrate approach over a cryogenic one is that separation process can be operated around the ice point, thus deep cooling can be avoided. Zhang et al. [5,6] have effectively separated $\mathrm{C}_{2} \mathrm{H}_{4}$ and $\mathrm{C}_{2} \mathrm{H}_{6}$ over $\mathrm{CH}_{4}$ by forming hydrates in aqueous solution, where it was found that both SDS and THF could increase the C2s' partition coefficient and recovery ratio. Naeiji et al. [7] studied the separation of methane-ethane mixtures of various compositions through hydrate formation. Their experimental data showed that the two gases could be fully separated, no matter whether the mole fractions of methane in the mixture were low or high. The separation of other components such as $\mathrm{CO}_{2}$ [8,9], $\mathrm{CH}_{4}$ [10], $\mathrm{H}_{2} \mathrm{~S}$ [11], $\mathrm{SF}_{6}$ [12], and HFC-134a [13], etc. by hydrate formation in aqueous solutions by adding hydrate additives were also widely investigated. However, these additives cannot guarantee the formation of flowable hydrate, which is required for the continuous separation of gas mixtures in practical industrial processes.

Rather than using a single phase aqueous solution, we recently proposed a new method for separating gas mixtures, the so-called absorption-hydration hybrid method. In this method, water-in-oil (W/O) emulsions are used under hydrate formation conditions [14-16]. The separation mechanism of this method is that gas components are firstly selectively absorbed by the oil phase due to the different solubility of each gas component and the dissolved gas molecules then further selectively form hydrate. This is to say there exists two separation processes in an equilibrium separation stage, thus high separation efficiency could be obtained. Anti-agglomerants added to the system could help hydrate particles suspend in the oil phase and prevent them from aggregating into blockages, thus a flowable hydrate slurry can be formed. In our previous works, we have effectively separated C2 from multicomponent refinery dry gases by using this absorption-hydration hybrid separation method and we found methane and ethylene are two critical components affecting the separation efficiency $[15,16]$. In order to understand more about the absorption-hydration hybrid method for the separation of hydrocarbons, determine the suitable operation conditions, and provide basic data for process design, in this work, the absorption-hydration hybrid method is adopted to recover $\mathrm{C}_{2} \mathrm{H}_{4}$ from binary $\mathrm{C}_{2} \mathrm{H}_{4} / \mathrm{CH}_{4}$ gas mixtures. 


\section{Results and Discussion}

A series of absorption-hydration separation experiments were performed for $\mathrm{C}_{2} \mathrm{H}_{4} / \mathrm{CH}_{4}$ mixtures using w/o emulsions under different hydrate formation conditions. The influences of initial gas-liquid volume ratio, pressure, temperature, water cuts, and gas composition on the emulsion's separation ability were studied systematically and the results are given in Tables $1-6$ and Figures 1 and 2.

Table 1. Separation results for $\mathrm{C}_{2} \mathrm{H}_{4} / \mathrm{CH}_{4}(30.08 / 69.92 \mathrm{~mol} \%)$ mixture in diesel-water emulsion with different initial gas-liquid ratio $\Phi$. Temperature and water cut were specified to $274.15 \mathrm{~K}$ and $30 \mathrm{vol} \%$, respectively.

\begin{tabular}{cccccccc}
\hline $\boldsymbol{P}_{\mathbf{0}} / \mathbf{M P a}$ & $\boldsymbol{P}_{\mathbf{E}} / \mathbf{M P a}$ & $\boldsymbol{P}_{\mathbf{E}}{ }^{\prime} / \mathbf{M P a}$ & $\boldsymbol{\Phi}$ & $\boldsymbol{y}_{\mathbf{1}}$ & $\boldsymbol{x}_{\mathbf{1}}$ & $\boldsymbol{R} / \mathbf{m o l} \%$ & $\boldsymbol{S}$ \\
\hline 2.2 & 1.65 & 1.55 & 53 & 19.02 & 53.63 & 57.00 & 4.92 \\
3.4 & 1.83 & 1.74 & 80 & 14.19 & 47.74 & 75.18 & 5.53 \\
4.2 & 2.38 & 1.81 & 109 & 12.77 & 46.50 & 79.19 & 5.94 \\
4.3 & 2.17 & 1.85 & 80 & 11.96 & 45.28 & 81.87 & 6.09 \\
5.0 & 2.31 & 1.90 & 80 & 10.99 & 43.27 & 85.07 & 6.18 \\
5.2 & 3.63 & 1.65 & 142 & 16.23 & 50.75 & 67.06 & 5.31 \\
\hline
\end{tabular}

Table 2. Separation results for $\mathrm{C}_{2} \mathrm{H}_{4} / \mathrm{CH}_{4}(30.08 / 69.92 \mathrm{~mol} \%)$ in diesel-water emulsion with different initial pressure. Temperature, initial gas-liquid volume ratio, and water cut were specified to $274.15 \mathrm{~K}, 80$, and $30 \mathrm{vol} \%$, respectively.

\begin{tabular}{ccccccc}
\hline $\boldsymbol{P}_{\mathbf{0}} / \mathbf{M P a}$ & $\boldsymbol{P}_{\mathbf{E}} / \mathbf{M P a}$ & $\boldsymbol{P}_{\mathbf{E}}{ }^{\prime} / \mathbf{M P a}$ & $\boldsymbol{y}_{\mathbf{1}}$ & $\boldsymbol{x}_{\mathbf{1}}$ & $\boldsymbol{R} / \mathbf{m o l} \%$ & $\boldsymbol{S}$ \\
\hline 3.4 & 1.83 & 1.74 & 14.19 & 47.74 & 75.18 & 5.53 \\
4.3 & 2.17 & 1.85 & 11.96 & 45.28 & 81.87 & 6.09 \\
5.0 & 2.31 & 1.90 & 10.99 & 43.27 & 85.07 & 6.18 \\
5.4 & 2.36 & 1.98 & 9.61 & 40.41 & 89.28 & 6.38 \\
\hline
\end{tabular}

Table 3. Separation results for $\mathrm{C}_{2} \mathrm{H}_{4} / \mathrm{CH}_{4}(30.08 / 69.92 \mathrm{~mol} \%)$ in diesel-water emulsion with different temperatures. Initial gas-liquid volume ratio, pressure, and water cut were specified to $80,3.4 \mathrm{MPa}$, and $30 \mathrm{vol} \%$, respectively.

\begin{tabular}{cccccc}
\hline $\boldsymbol{P}_{\mathbf{E}} / \mathbf{M P a}$ & $\boldsymbol{T} / \mathbf{K}$ & $\boldsymbol{y}_{\mathbf{1}}$ & $\boldsymbol{x}_{\mathbf{1}}$ & $\boldsymbol{R} / \mathbf{m o l} \%$ & $\boldsymbol{S}$ \\
\hline 1.83 & 274.15 & 14.19 & 47.74 & 75.18 & 5.53 \\
1.96 & 275.15 & 16.03 & 48.02 & 70.12 & 4.84 \\
2.09 & 276.15 & 17.21 & 49.59 & 65.55 & 4.73 \\
2.10 & 277.15 & 18.66 & 51.19 & 59.75 & 4.57 \\
2.29 & 278.15 & 19.69 & 52.29 & 55.42 & 4.47 \\
\hline
\end{tabular}

Table 4. Separation results for $\mathrm{C}_{2} \mathrm{H}_{4} / \mathrm{CH}_{4}(30.08 / 69.92 \mathrm{~mol} \%)$ in diesel-water emulsion with different water cuts. Temperature, initial pressure, and initial gas-liquid volume ratio were specified to $274.15 \mathrm{~K}, 3.4 \mathrm{MPa}$, and 80 , respectively.

\begin{tabular}{cccccc}
\hline $\boldsymbol{P}_{\mathrm{E}} / \mathbf{M P a}$ & $\boldsymbol{Q}_{\mathrm{W}} / \boldsymbol{\%}$ & $\boldsymbol{y}_{\mathbf{1}}$ & $\boldsymbol{x}_{\mathbf{1}}$ & $\boldsymbol{R} / \mathbf{m o l} \%$ & $\boldsymbol{S}$ \\
\hline 1.88 & 10 & 17.04 & 49.04 & 66.43 & 4.68 \\
1.77 & 15 & 15.22 & 48.68 & 71.88 & 5.28 \\
1.73 & 20 & 14.57 & 48.28 & 73.85 & 5.47 \\
1.71 & 30 & 14.19 & 47.74 & 75.18 & 5.53 \\
\hline
\end{tabular}


Table 5. Separation results for $\mathrm{C}_{2} \mathrm{H}_{4} / \mathrm{CH}_{4}(30.08 / 69.92$ mol\%) mixture in diesel-water emulsion. Initial gas-liquid ratio $\Phi$, initial pressure, temperature, and water cut were specified to $80,4.2 \mathrm{MPa}, 274.15 \mathrm{~K}$, and $20 \mathrm{vol} \%$, respectively.

\begin{tabular}{cccccc}
\hline $\boldsymbol{P}_{\mathbf{0}} / \mathbf{M P a}$ & $\boldsymbol{P}_{\mathrm{E}} / \mathbf{M P a}$ & $\boldsymbol{y}_{\mathbf{1}}$ & $\boldsymbol{x}_{\mathbf{1}}$ & $\boldsymbol{R} / \mathbf{m o l} \%$ & $\boldsymbol{S}$ \\
\hline 4.2 & 2.46 & 13.13 & 45.68 & 79.08 & 5.56 \\
\hline
\end{tabular}

Table 6. Vapor-hydrate equilibrium data for $\mathrm{C}_{2} \mathrm{H}_{4} / \mathrm{CH}_{4}$ binary system in diesel-water emulsion with respect to six feed gas mixtures with different compositions while temperature, initial pressure, and water cut are $274.15 \mathrm{~K}, 3.4 \mathrm{MPa}$, and $30 \mathrm{vol} \%$, respectively.

\begin{tabular}{ccccccc}
\hline $\boldsymbol{P}_{\mathrm{E}} / \mathbf{M P a}$ & $\boldsymbol{\Phi}(\mathbf{v} / \mathbf{v})$ & $\boldsymbol{Z}_{\mathbf{1}}$ & $\boldsymbol{y}_{\mathbf{1}}$ & $\boldsymbol{x}_{\mathbf{1}}$ & $\boldsymbol{R} / \mathbf{m o l} \%$ & $\boldsymbol{S}$ \\
\hline 2.34 & 75 & 13.19 & 8.71 & 21.53 & 57.08 & 2.88 \\
2.20 & 77 & 20.84 & 11.97 & 34.28 & 65.39 & 3.83 \\
1.93 & 80 & 30.08 & 14.19 & 47.95 & 75.04 & 5.57 \\
1.77 & 85 & 48.43 & 26.53 & 67.04 & 76.83 & 5.63 \\
1.46 & 103 & 61.22 & 41.57 & 70.17 & 78.75 & 3.31 \\
1.48 & 112 & 80.44 & 64.52 & 86.73 & 76.38 & 3.49 \\
\hline
\end{tabular}

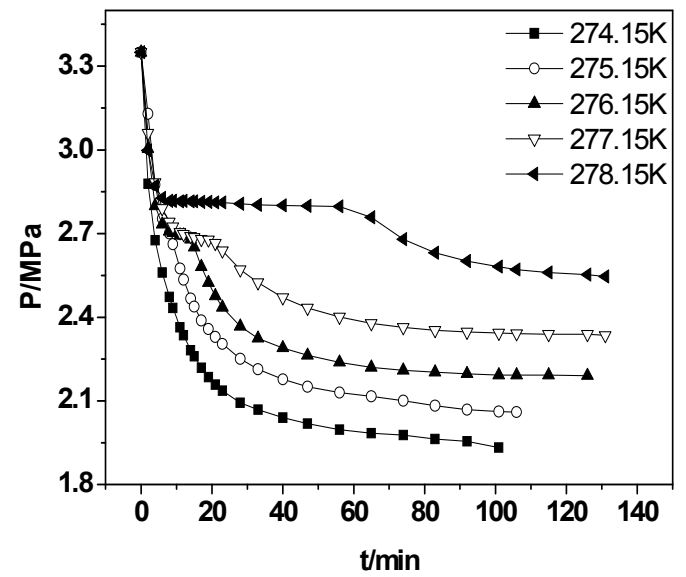

Figure 1. Kinetic curves of $\mathrm{C}_{2} \mathrm{H}_{4} / \mathrm{CH}_{4}(30.08 / 69.92 \mathrm{~mol} \%)$ mixture separation in $\mathrm{W} / \mathrm{O}$ emulsion at fixed initial pressure $3.4 \mathrm{MPa}$ but different temperatures.

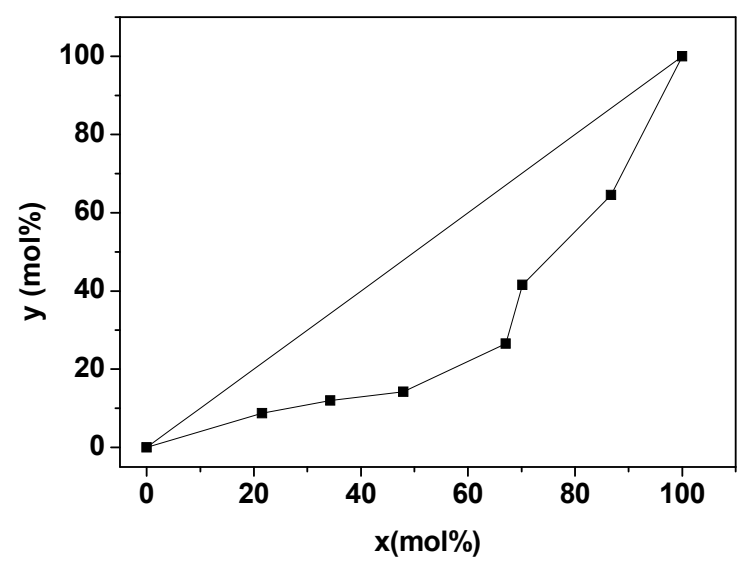

Figure 2. Pseudo- $\mathrm{x}-\mathrm{y}$ diagram of $\mathrm{C}_{2} \mathrm{H}_{4} / \mathrm{CH}_{4}$ binary systems. Temperature, initial pressure, and water cut are $274.15 \mathrm{~K}, 3.4 \mathrm{MPa}$, and $30 \mathrm{vol} \%$, respectively. 


\subsection{Effect of Initial Gas-Liquid Volume Ratio and Pressure}

Table 1 shows the influence of initial gas-liquid volume ratio and pressure upon the separation efficiency of ethylene with respect to a $\mathrm{C}_{2} \mathrm{H}_{4} / \mathrm{CH}_{4}(30.08 / 69.92 \mathrm{~mol} \%)$ feed gas. In this group of experiments, temperature and water cut were specified to $274.15 \mathrm{~K}$ and 30 vol\%, respectively. $P_{0}$ and $P_{\mathrm{E}}$ are the initial pressure and equilibrium pressure in the sapphire cell, respectively; $P_{\mathrm{E}}$ ' is the hydrate formation pressure of residual $\mathrm{C}_{2} \mathrm{H}_{4} / \mathrm{CH}_{4}$ mixture in the sapphire cell; $y_{1}$ and $x_{1}$ are the mole fraction of $\mathrm{C}_{2} \mathrm{H}_{4}$ in equilibrium gas phase and slurry phase; $R$ is the recovery ratio of $\mathrm{C}_{2} \mathrm{H}_{4}$ in the slurry phase; and $S$ is the separation factor of $\mathrm{C}_{2} \mathrm{H}_{4}$ over $\mathrm{CH}_{4}$. From Table 1 we can see the separation ability of the absorption-hydration hybrid method increases remarkably with the increase of $\Phi$ and $P_{0}$ as $y_{1}$ decreases and both $R$ and $S$ increase. This can be attributed to the fact that under higher $\Phi$, more water is converted into hydrate, which increased the hydration separation ability dramatically. However, as shown in Table 1, when the initial gas-liquid volume ratio $(\Phi)$ increased to 109 , the hydrate formation pressure of residual $\mathrm{C}_{2} \mathrm{H}_{4} / \mathrm{CH}_{4}(12.77 / 87.23 \mathrm{~mol} \%)$ mixture in the sapphire cell is only about $1.81 \mathrm{MPa}$ as calculated by Chen-Guo model [17]. This formation pressure is much lower than the equilibrium separation pressure $(2.38 \mathrm{MPa})$, indicating all water has converted to hydrate under these conditions and the V-Lhydrocarbon-rich-H three-phase equilibrium has been established after the completion of hydrate formation. This can also be proved from another series of experimental runs listed in Table 2, where the experimental temperature and initial gas-liquid volume ratio were respectively specified at $274.15 \mathrm{~K}$ and 80 but under different initial pressures by pushing the piston in the sapphire cell after gases were injected into it. As one can see, when the initial pressure $\left(P_{0}\right)$ is higher than 4.3 $\mathrm{MPa}$, the equilibrium pressure $\left(P_{\mathrm{E}}\right)$ becomes remarkably higher than $\mathrm{V}$-Lhydrocarbon-rich-W-H four-phase equilibrium pressure $P_{\mathrm{E}}$, indicating all water has been converted into hydrate and $\mathrm{V}$-Lhydrocarbon-rich-H three-phase equilibrium exists in the sapphire cell in these cases. From Table 2 we can also see that $y_{1}$ and the separation factor $S$ just change a little with increasing the initial pressure when all water has been converted into hydrate, so in a practical separation process, the appropriate initial gas-liquid volume ratio and operation pressure should be less than 100 and $4.2 \mathrm{MPa}$, respectively, in order to not be working in a V-Lhydrocarbon-rich-H three phase co-existence area.

\subsection{Effect of Temperature}

Table 3 shows the influence of temperature upon the separation efficiency of ethylene with respect to the same $\mathrm{C}_{2} \mathrm{H}_{4} / \mathrm{CH}_{4}$ feed gas. The initial pressure and the initial gas-liquid volume ratio were specified at 3.4 MPa and 80, respectively. It is evident that the concentration of $\mathrm{C}_{2} \mathrm{H}_{4}$ in the equilibrium gas phase $\left(y_{1}\right)$ decreases and the fraction of $\mathrm{C}_{2} \mathrm{H}_{4}$ recycled from feed gas $(R)$ and the separation factor $(S)$ increases quickly when the temperature decreases from $278.15 \mathrm{~K}$ to $274.15 \mathrm{~K}$. This is due to an increase of the quantity of hydrate formed with decreasing temperature. As can be seen, when the temperature is $274.15 \mathrm{~K}$, after a single equilibrium separation stage, the mole fraction of $\mathrm{C}_{2} \mathrm{H}_{4}$ could be enriched from 30.08 to $48 \mathrm{~mol} \%$ in the hydrate slurry. Under this condition, the separation factor $S$ reached 5.53 and more than $75 \%$ of $\mathrm{C}_{2} \mathrm{H}_{4}$ could be recovered from the slurry, demonstrating the good separation ability of the absorption-hydration method. Figure 1 shows the kinetic behaviors of the phase equilibrium process for $\mathrm{C}_{2} \mathrm{H}_{4} / \mathrm{CH}_{4}$ mixture at these four different temperatures. As one can see 
there are three sequential stages, i.e., gas dissolution, induction of hydrate nucleation, and hydrate growth, for a single kinetic behavior. The first rapid decrease of pressure corresponds to the dissolution of gas in the oil phase. One can see that the induction time decreased and the hydrate formation rate increased dramatically with decreasing temperature. This can be attributed to a result of an increase of the driving force for hydrate formation. When temperature dropped to $275.15 \mathrm{~K}$, the induction period nearly disappeared. In addition, from Figure 1 we can see that most hydrate formation finished in $20 \mathrm{~min}$, and after that, hydrate formation rate became very slow. It should be pointed out that if using pure water instead of w/o emulsion, the induction time is always more than half an hour and the formation rate of hydrate is very slow then [18]. As higher hydrate formation rates are always pursued in practical applications to increase the efficiency of a separation process and reduce the scales of the equipment involved, kinetic behavior should be given more weight when determining the operation conditions. Experimental results obtained here means the suitable operation temperature is approximately $274.15 \mathrm{~K}$.

\subsection{Effect of Water Cuts}

Water cut $\left(Q_{\mathrm{w}}\right)$ is an important factor to evaluate the separation capacity. Higher water cut means more hydrate formation and larger gas processing of the w/o emulsion. Therefore, a group of separation experiments on the same $\mathrm{C}_{2} \mathrm{H}_{4} / \mathrm{CH}_{4}$ mixture with four different water cuts were performed to evaluate the influence of $Q_{\mathrm{w}}$ on the separation results of absorption-hydration hybrid method, where the content of Span 20 added in water phase is still $1.0 \mathrm{wt} \%$. Temperature, initial pressure, and initial gas-liquid volume ratio were specified to $274.15 \mathrm{~K}, 3.4 \mathrm{MPa}$, and $\sim 80$, respectively. As shown in Table 4, both the separation factor $S$ and the recovery ratio $R$ of $\mathrm{C}_{2} \mathrm{H}_{4}$ increased with increasing water cuts. This demonstrates that a higher water cut is favorable for the recovery of $\mathrm{C}_{2} \mathrm{H}_{4}$ from $\mathrm{C}_{2} \mathrm{H}_{4} / \mathrm{CH}_{4}$ mixtures using the absorption-hydration method. Although a higher water cut allows a greater contribution of hydrate separation to the entire absorption-hydration separation process, it was found that the hydrate slurry formed from the emulsions with higher water cuts had higher viscosities. Therefore, more energy would be needed for the transportation of the hydrate slurry in practical separation processes. More seriously, when water cut is higher than $30 \mathrm{vol} \%$, it might become impossible for the hydrate slurry to flow [19]. From Table 4 you can see when water cut increases from 20 to 30 vol\%, both $R$ and $S$ increase by only $1.5 \%$ or so. As the formation of stable and flowable hydrate slurry is critical for the absorption-hydration hybrid separation approach, in view of both separation efficiency and energy cost, here we recommend that water cut should be around $20 \mathrm{vol} \%$ in practical use.

In addition, an experiment with all of optimized conditions has been carried out and the results are given in Table 5. From Table 5 we can see the separation efficiency of $\mathrm{C}_{2} \mathrm{H}_{4} / \mathrm{CH}_{4}$ mixtures by forming hydrate in w/o emulsion is very promising.

\subsection{Effect of Gas Compositions}

Gas composition is another important factor to evaluate the emulsion's separation capacity as refinery gases or cracking gases, etc. have different concentrations of $\mathrm{C}_{2} \mathrm{H}_{4}$. Table 6 displays the separation results for six different $\mathrm{C}_{2} \mathrm{H}_{4} / \mathrm{CH}_{4}$ mixtures in w/o emulsion, where $T$, $P_{0}$, and water cut are 274.15 K, 3.4 MPa, and $30 \mathrm{vol} \%$. As shown in Table 6, equilibrium pressure $\left(P_{\mathrm{E}}\right)$ decreases with the increase of $z_{1}$, while for $S$, there exists a suitable $z_{1}$, i.e., $48 \mathrm{~mol} \%$ or so, at which the highest $S$ 
was obtained. We think it could be attributed to the fact that under this condition, $z_{1}$ is close to the critical value at which the V-Lhydrocarbon-rich- $\mathrm{L}_{\text {water-rich-H }} \mathrm{H}$ four-phase equilibrium converts to the $\mathrm{V}$-Lhydrocarbon-rich-H three phase equilibrium. When $z_{1}$ exceeded $48 \mathrm{~mol} \%$, all water was converted into hydrate and the V-Lhydrocarbon-rich-H three phase equilibrium was established after the completion of hydrate formation. In this case, the quantity of hydrate did not increase with increasing $z 1$. However, the amount of $\mathrm{C}_{2} \mathrm{H}_{4}$ dissolved in the oil phase increased with $z_{1}$ and the contribution of the absorption separation to the entire hybrid separation increased with $z_{1}$. Because the separation factor of single absorption is lower than that of hydration as stated in our previous works $[15,16]$, the separation factor of the entire absorption-hydration hybrid process decreased with increasing $z_{1}$. Separation results obtained here implies that it is very feasible to recover $\mathrm{C}_{2} \mathrm{H}_{4}$ for $\mathrm{C}_{2} \mathrm{H}_{4} / \mathrm{CH}_{4}$ mixtures by using the absorption-hydration hybrid method. In order to display the separation efficiencies of $\mathrm{C}_{2} \mathrm{H}_{4} / \mathrm{CH}_{4}$ mixtures by forming hydrate and the vapor-slurry equilibrium behavior of this binary system, the P-T-X-y data listed in Table 6 were used to produce a pseudo-x-y diagram, i.e., Figure 2, which clearly shows that the separation efficiency of $\mathrm{C}_{2} \mathrm{H}_{4} / \mathrm{CH}_{4}$ mixtures by forming hydrate in w/o emulsions is very encouraging in the lower to medium ethylene concentration range.

\section{Experimental Section}

\subsection{Experimental Apparatus}

A schematic diagram of the experimental apparatus, which has been described in detail in our previous work [16], is shown in Figure 3. The main part of the apparatus is a high-pressure sapphire cell, in which gas mixtures contact with a w/o emulsion. Another important part is a blind cell, in which feed gas is pre-stored. The mole number of feed gas injected into the sapphire cell can be determined precisely through the pressure drop in the cell at a given temperature.

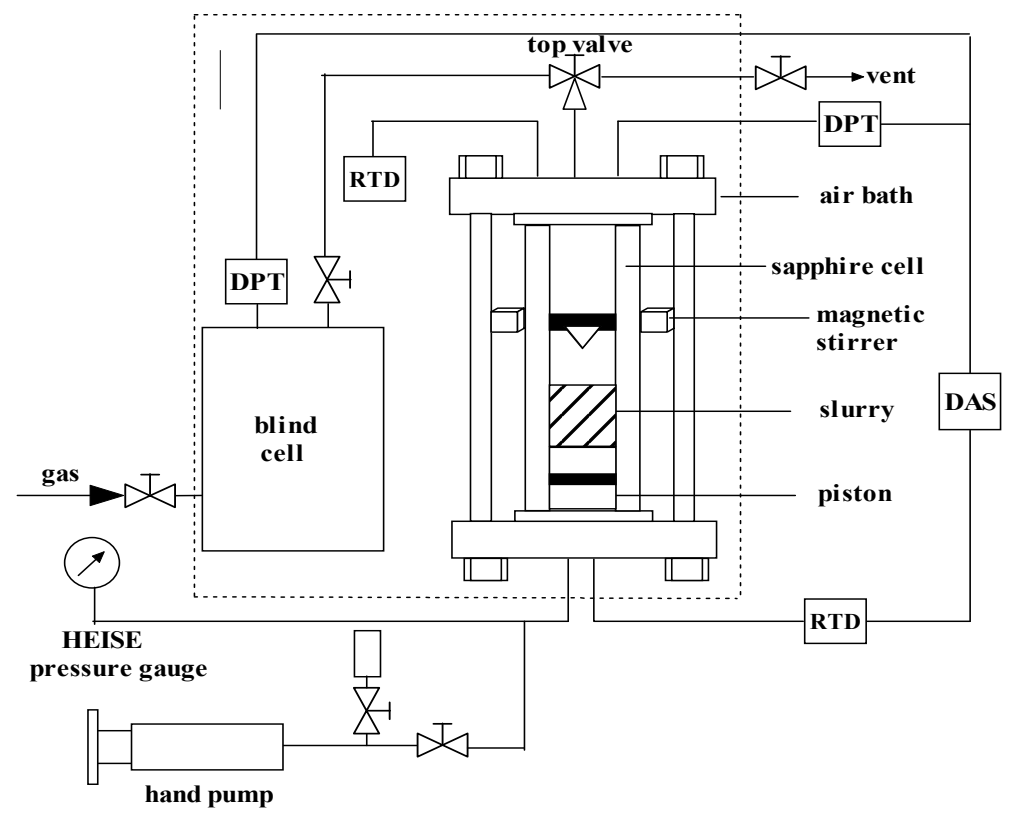

Figure 3. Schematic diagram of the experimental apparatus for hydrate formation: RTD, resistance thermocouple detector; DPT, differential pressure transducer; and DAS, data acquisition system. 


\subsection{Materials and Preparation of Samples}

Analytical grade methane (99.99\%) and ethylene (99.99\%) were purchased from Beijing AP Beifen Gas Industry Company (Beijing, China). The diesel, with a freezing point of $263.2 \mathrm{~K}$, was purchased from Sinopec (Beijing, China). The synthetic $\mathrm{C}_{2} \mathrm{H}_{4} / \mathrm{CH}_{4}(30.08 / 69.92 \mathrm{~mol} \%)$ gas mixtures were prepared by ourselves. A Hewlett-Packard gas chromatograph (HP 7890, Hewlett-Packard Development Company, Palo Alto, CA, USA) was used to analyze the composition of the synthetic gases and residual gases after separation equilibrium. An electronic balance with a precision of $\pm 0.1 \mathrm{mg}$ was used in preparing the emulsion system with the required water cut and the content of Span 20. Span 20 was supplied by Beijing Reagents Corporation (Beijing, China). In all experimental runs, the mass content of Span 20 added in water was specified at $1 \%$.

\subsection{Experimental Procedures}

Prior to the experiment, the sapphire cell was dismounted from the apparatus, washed with distilled water and dried. Next, $20 \mathrm{~mL}$ of liquid sample, e.g., water in diesel emulsion, was added into it. The system (sapphire cell + blind cell + tubes connecting two cells) was then purged through vacuuming, being replaced with feed gas, and vacuuming in turn to ensure the absence of air. Subsequently, the feed gas was injected into the blind cell until pressure was high enough. The air-bath temperature was then adjusted to the desired value. Once both temperature and pressure of the blind cell are constant, the desired amount of feed gas was injected into the sapphire cell from the blind cell and the magnetic stirrer was started to accelerate the hydrate formation. With absorption and hydration of gas mixtures, the system pressure in the sapphire cell decreased gradually. The change of pressure with elapsed time was recorded by a computer. When the system pressure became a constant for a long time, the formation of hydrate was assumed to be finished. The equilibrium gas mixture in the sapphire cell was then sampled under the constant pressure by pushing the piston in the sapphire cell using a hand pump and the compositions of the gas mixture were analyzed by the HP 7890 gas chromatograph. It should be pointed out that temperature of the air bath was kept constant during each experimental run. The volume of the emulsion or slurry phase in the sapphire cell can be obtained by measuring its height because the inner radius of the sapphire cell is known to be $1.27 \mathrm{~cm}$. After each experimental run, the system was depressurized to atmospheric pressure and temperature was increased to $298 \mathrm{~K}$ or so to decompose hydrate thoroughly. Finally the cell was cleaned for the next experimental run.

\subsection{Experimental Data Processing}

In this work, the gas composition in slurry phase after separation equilibrium was determined by mass balance based on the following equations $[15,16]$.

The total mole number of gas mixture $\left(n_{\mathrm{t}}\right)$ that injected into the sapphire cell was calculated by the following formula:

$$
n_{t}=\frac{P_{1} V_{\mathrm{t}}}{Z_{0} R T}-\frac{P_{2} V_{\mathrm{t}}}{Z_{1} R T}
$$


where $P_{1}$ and $P_{2}$ are pressures of the blind cell before and after gas mixture was injected into the sapphire cell, respectively; $V_{\mathrm{t}}$ is the total volume of the blind cell plus tubes connected to it; $T$ is the system temperature; $R$ is the universal gas constant. The compressibility factors $Z_{0}$ and $Z_{1}$ were calculated with the Benedict-Webb-Rubin-Starling equation of state. The total gas amount $(n \mathrm{E})$ in the equilibrium gas phase of the sapphire cell after absorption and adsorption equilibrium is determined by:

$$
n_{\mathrm{E}}=\frac{P_{\mathrm{E}} V_{\mathrm{g}}}{Z_{\mathrm{E}} R T}
$$

where $P_{\mathrm{E}}$ is the equilibrium pressure of the sapphire cell and $Z_{\mathrm{E}}$ is the compressibility factor corresponding to $P_{\mathrm{E}}$ and $T$. $V_{\mathrm{g}}$ is the volume of equilibrium gas phase in the sapphire cell at the end of each experiment run. The total uptake of $\mathrm{C}_{2} \mathrm{H}_{4}\left(n_{1}\right)$ and $\mathrm{CH}_{4}\left(n_{2}\right)$ in the hydrate slurry are calculated as follows:

$$
\begin{aligned}
& n_{1}=n_{\mathrm{t}} \mathrm{z}_{1}-n_{\mathrm{E}} y_{1} \\
& n_{2}=n_{\mathrm{t}} \mathrm{z}_{2}-n_{\mathrm{E}} y_{2}
\end{aligned}
$$

where $z_{\mathrm{i}}$ and $y_{\mathrm{i}}$ are the mole fractions of $\mathrm{C}_{2} \mathrm{H}_{4}$ and $\mathrm{CH}_{4}$ in the feed gas and equilibrium gas phase, respectively. After that, the mole fractions of them in the equilibrium hydrate slurry phase can be obtained by the following formulas:

$$
\begin{aligned}
& x_{1}=\frac{n_{1}}{n_{1}+n_{2}} \\
& x_{2}=\frac{n_{2}}{n_{1}+n_{2}}
\end{aligned}
$$

In this work the separation factor $(S)$ of $\mathrm{C}_{2} \mathrm{H}_{4}$ over $\mathrm{CH}_{4}$ and the recovery ratio $(R)$ of $\mathrm{C}_{2} \mathrm{H}_{4}$ in slurry phase are used to indicate the separation ability of the method adopted here:

$$
\begin{gathered}
S=\frac{x_{1} / y_{1}}{x_{2} / y_{2}} \\
R=\left(1-\frac{n_{E} y_{1}}{n_{t} z_{1}}\right) \times 100 \%
\end{gathered}
$$

The initial gas-emulsion volume ratio $(\Phi)$ is defined as

$$
\varphi=\frac{22400 n_{t}}{V_{S}}
$$

where $V_{\mathrm{s}}$ is the volume of the emulsion.

\section{Conclusions}

In this work, an absorption-hydration hybrid method was employed to recover $\mathrm{C}_{2} \mathrm{H}_{4}$ from $\mathrm{C}_{2} \mathrm{H}_{4} / \mathrm{CH}_{4}$ mixtures. Span 20 was used to disperse water or hydrate in diesel to form emulsions or hydrate slurries. The effects of initial gas-liquid volume ratio, initial pressure, temperature, and water cuts on 
the separation ability of $\mathrm{C}_{2} \mathrm{H}_{4}$ from $\mathrm{C}_{2} \mathrm{H}_{4} / \mathrm{CH}_{4}$ mixtures in w/o emulsions were systematically investigated. The experimental results show the separation efficiency of $\mathrm{C}_{2} \mathrm{H}_{4} / \mathrm{CH}_{4}$ mixtures by forming hydrate in w/o emulsions is very promising in the lower to medium $\mathrm{C}_{2} \mathrm{H}_{4}$ concentration range. It implies that it is very feasible to recover ethylene from various kinds of refinery gases or cracking gases in an ethylene plant by the absorption-hydration hybrid method.

\section{Acknowledgments}

Financial support received from the National Natural Science Foundation of China (No. U1162205), the Program for New Century Excellent Talents from Ministry of Education (NCET-12-0968), Beijing Youth Talent Plan (YETP0674), and the Research Funds of China University of Petroleum, Beijing (2462013YXBS005) is gratefully acknowledged.

\section{Author Contributions}

Bei Liu and Guangjin Chen designed the experiments; Bei Liu and Guangjin Chen led data analysis. Yong Pan, Huang Liu, Lanying Yang and Xueteng Gao performed laboratory experiments. Yong Pan, Huang Liu, Bei Liu, Qinglan Ma, Guangjin Chen and Changyu Sun performed data analysis. Huang Liu prepared figures and tables. Huang Liu, Zhi Li and Bei Liu wrote the manuscript.

\section{Conflicts of Interest}

The authors declare no conflict of interest.

\section{References}

1. Baker, R.W. Future directions of membrane gas separation technology. Ind. Eng. Chem. Res. 2002, 41, 1393-1411.

2. He, Y.; Zhang, Z.; Xiang, S.; Wu, H.; Fronczek, F.R.; Zhou, W.; Krishna, R.; O'Keeffe, M.; Chen, B. High separation capacity and selectivity of C2 hydrocarbons over methane within a microporous metal-organic framework at room temperature. Chem. Eur. J. 2012, 18, 1901-1904.

3. Li, K.; Olson, D.H.; Seidel, J.; Emge, T.J.; Gong, H.; Zeng, H.; Li, J. Zeolitic imidazolate frameworks for kinetic separation of propane and propene. J. Am. Chem. Soc. 2009, 131, 10368-10369.

4. Sloan, E.D. Clathrate Hydrates of Natural Gases, 2nd ed.; Marcel Dekker: New York, NY, USA, 1998.

5. Zhang, L.W.; Chen, G.J.; Guo, X.Q.; Sun, C.Y.; Yang, L.Y. The partition coefficients of ethane between vapor and hydrate phase for methane + ethane + water and methane + ethane $+\mathrm{THF}+$ water systems. Fluid Phase Equilib. 2004, 225, 141-144.

6. Zhang, L.W.; Chen, G.J.; Sun, C.Y.; Fan, S.S.; Ding, Y.M.; Wang, X.L.; Yang, L.Y. The partition coefficients of ethylene between hydrate and vapor for methane + ethylene + water and methane + ethylene + SDS + water systems. Chem. Eng. Sci. 2005, 60, 5356-5362.

7. Naeiji, P.; Mottahedin, M.; Varaminian, F. Separation of methane-ethane gas mixtures via gas hydrate formation. Sep. Purif. Technol. 2014, 123, 139-144. 
8. Kang, S.P.; Lee, H. Recovery of $\mathrm{CO}_{2}$ from flue gas using gas hydrate: Thermodynamic verification through phase equilibrium measurements. Environ. Sci. Technol. 2000, 34, 4397-4400.

9. Li, X.S.; Xu, C.G.; Chen, Z.Y.; Cai, J. Synergic effect of cyclopentane and tetra-n-butyl ammonium bromide on hydrate-based carbon dioxide separation from fuel gas mixture by measurements of gas uptake and X-ray diffraction patterns. Int. J. Hydrog. Energy 2012, 37, $720-727$.

10. Zhong, D.L.; Englezos, P. Methane separation from coal mine methane gas by tetra-n-butyl ammonium bromide semiclathrate hydrate formation. Energy Fuels 2012, 26, 2098-2106.

11. Kamata, Y.; Yamakoshi, Y.; Ebinuma, T.; Oyama, H.; Shimada, W.; Narita, H. Hydrogen sulfide separation using tetra-n-butyl ammonium bromide semi-clathrate (TBAB) hydrate. Energy Fuels 2005, 19, 1717-1722.

12. Cha, I.; Lee, S.; Lee, J.D.; Lee, G.W.; Seo, Y. Separation of SF 6 from gas mixtures using gas hydrate formation. Environ. Sci. Technol. 2010, 44, 6117-6122.

13. Tajima, H.; Nagata, T.; Abe, Y.; Yamasaki, A.; Kiyono, F.; Yamagiwa, K. HFC-134a hydrate formation kinetics during continuous gas hydrate formation with a kenics static mixer for gas separation. Ind. Eng. Chem. Res. 2010, 49, 2525-2532.

14. Wang, X.L.; Chen, G.J.; Yang, L.Y.; Zhang, L.W. Study on the recovery of hydrogen from refinery (hydrogen + methane) gas mixtures using hydrate technology. Sci. China Ser. B 2008, 51, 171-178.

15. Liu, H.; Mu, L.; Liu, B.; Zhang, X.X.; Wang, J.; Wang, B.; Sun, C.Y.; Yang, L.Y.; Wang, H.; Xiao, P.; et al. Experimental studies of the separation of $\mathrm{C} 2$ compounds from $\mathrm{CH}_{4}+\mathrm{C}_{2} \mathrm{H}_{4}+\mathrm{C}_{2} \mathrm{H}_{6}$ $+\mathrm{N}_{2}$ gas mixtures by absorption-hydration hybrid method. Ind. Eng. Chem. Res. 2013, 52, 2707-2713.

16. Liu, H.; Mu, L.; Wang, B.; Liu, B.; Wang, J.; Zhang, X.X.; Sun, C.Y.; Chen, J.; Jia, M.L.; Chen, G.J. Separation of ethylene from refinery dry gas via forming hydrate in w/o dispersion system. Sep. Purif. Technol. 2013, 116, 342-350.

17. Chen, G.J.; Guo, T.M. Thermodynamic modeling of hydrate formation based on new concepts. Fluid Phase Equilib. 1996, 122, 43-65.

18. Van Denderen, M.; Ineke, E.; Golombok, M. $\mathrm{CO}_{2}$ removal from contaminated natural gas mixtures by hydrate formation. Ind. Eng. Chem. Res. 2009, 48, 5802-5807.

19. Peng, B.Z.; Chen, J.; Sun, C.Y.; Dandekar, A.; Guo, S.H.; Liu, B.; Mu, L.; Yang, L.Y.; Li, W.Z.; Chen, G.J. Flow characteristics and morphology of hydrate slurry formed from (natural gas + diesel oil/condensate oil + water) system containing anti-agglomerant. Chem. Eng. Sci. 2012, 84, 333-344.

(C) 2015 by the authors; licensee MDPI, Basel, Switzerland. This article is an open access article distributed under the terms and conditions of the Creative Commons Attribution license (http://creativecommons.org/licenses/by/4.0/). 